\title{
TEKNIK PENGAMBILAN MAKROZOOBENTOS DI DAERAH PULAU PAYUNG, SUNGAI MUSI, SUMATERA SELATAN
}

\author{
Mirna Dwirastina \\ Teknisi Litkayasa pada Balai Riset Perikanan Perairan Umum, Mariana-Palembang \\ Teregristasi I tanggal: 23 Juli 2008; Diterima setelah perbaikan tanggal: 24 Juli 2008; \\ Disetujui terbit tanggal: 24 Juli 2008
}

\section{PENDAHULUAN}

Bentos adalah organisme dasar perairan, baik berupa hewan maupun tumbuhan, hidup di permukaan dasar ataupun di dasar perairan. Bentos dapat digolongkan fitobentos berupa tumbuhan dan zoobentos berupa hewan. Berdasarkan pada ukuran terdiri atas makrobentos, mesobentos, dan mikrobentos. Makrobentos adalah organisme yang hidup di dasar perairan dan tersaring oleh saringan yang berukuran $1,0 \times 1,0 \mathrm{~mm}$ atau $2,0 \times 2,0 \mathrm{~mm}$, yang pada pertumbuhan dewasa berukuran 3-5 mm. Mesobentos merupakan organisme yang mempunyai ukuran 0,1-1,0 mm. Sedangkan mikrobentos adalah organisme di dasar yang ukuran antara 0,1-1,0 mm (Fachrul, 2007). Pengambilan bentos di perairan dimaksudkan sebagai organisme indikator kualitas perairan karena sifat bentos yang relatif diam atau memiliki mobilitas yang rendah sehingga banyak mendapat pengaruh dari lingkungan (Hawkes, 1979).

Pulau Payung merupakan daerah estuaria Sungai Musi, berdekatan dengan Muara Sungsang. Pengambilan contoh bentos di daerah ini yaitu mengambil makrobentos (Gambar 1). Pengambilan contoh ini menggunakan metode pengambilan contoh komunitas fauna bentik (zoobentos).

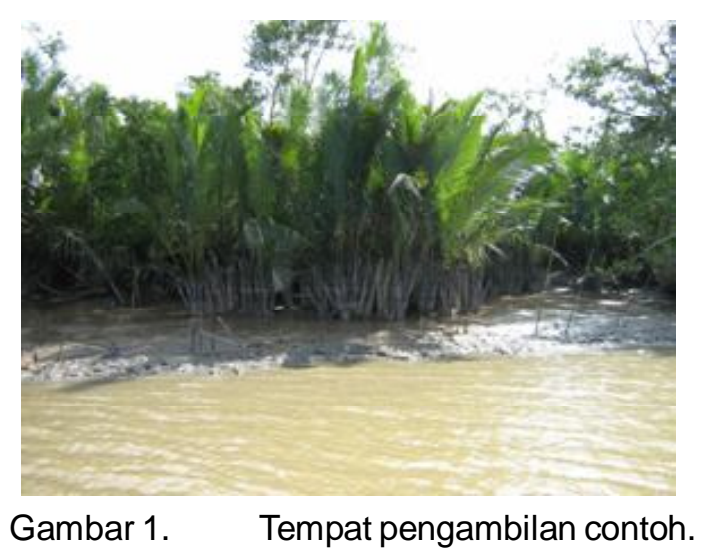

Tujuan penulisan makalah ini adalah untuk menginformasikan teknik pengambilan bentos dan jenis-jenis makrobentos yang ada di daerah Pulau payung tersebut.

\section{POKOK BAHASAN}

\section{Bahan dan Alat}

Pengambilan contoh bentos membutuhkan bahan larutan rosbengel dan formalin $10 \%$. Alat-alat yang digunakan adalah mikroskop, ekman grab, baskom atau ember, saringan bentos, pipet, plastik, dan spidol permanen.

\section{Cara Kerja}

\section{Pengambilan Contoh Lapangan}

1. Ambil contoh bentos dengan menggunakan Ekman Grab, terbuat dari baja tahan karat dengan bobot $3,2 \mathrm{~kg}$ dengan ukuran $30 \times 30 \mathrm{~cm} ; 23 \times 23 \mathrm{~cm}$; dan $15 \times 15 \mathrm{~cm}$ (APHA, 2005). Caranya adalah dengan mengambil 5 titik contoh pada sisi kanan dan kiri pada lokasi tersebut dan dikomposit.

2. Substrat yang sudah terambil dengan menggunakan ekman grab tersebut dimasukkan dalam baskom atau ember bervolume $10 \mathrm{~L}$ (Gambar 2).

3. Kemudian subsrat yang telah didapat disaring menggunakan saringan no.30 $(0,85 \mathrm{ml})$ (APHA, 2005).

4. Setelah disaring, substrat tersebut dimasukkan dalam plastik dan diberi label dan ditulis nama lokasi serta tanggal pengambilan contoh. Kemudian substrat tersebut diberi pengawet formalin $10 \%$ sampai dengan substrat tenggelam dan ditetesin rosbengel sampai dengan berwarna 
merah. Kemudian diaduk-aduk sampai semua substrat di pastikan teraduk semua .

\section{Pemeriksaan Laboratorium}

1. Substrat di keluarkan dalam plastik dan dicuci dengan air tawar agar bau formalin berkurang.

2. Substrat mulai disortir dengan cara memisahkan antara mikro organisme dengan serasah atau sampah (Gambar 3).
3. Hasil sortir dimasukkan dalam botol contoh yang berukuran $25 \mathrm{ml}$ dan di beri pengawet formalin $10 \%$.

4. Pengamatan dilakukan menggunakan mikroskop elektrik dan identifikasi menggunakan buku-buku identifikasi.

\section{Gambar 2.}

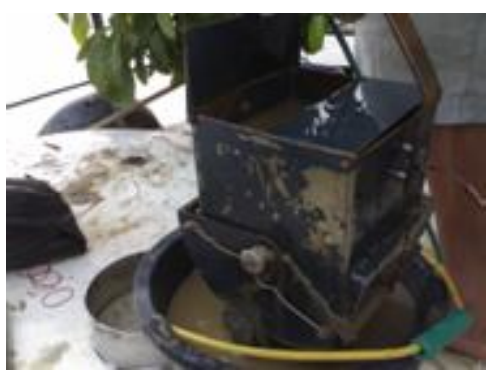

Contoh dimasukkan dalam ember plastik.

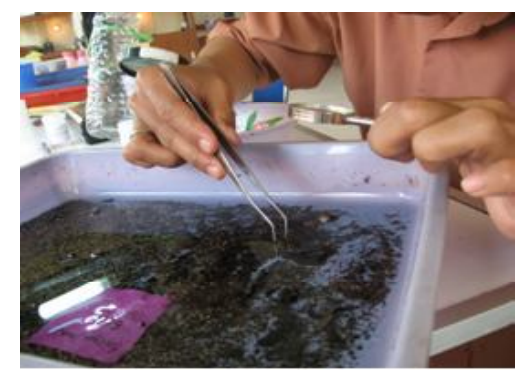

Gambar 3. Proses penyortiran.

\section{Hasil Pengamatan}

Hasil pengamatan makrozoobentos dari perairan di daerah Pulau Payung tercantum pada Tabel 1. Pada daerah Pulau Payung ini ditemukan 2 jenis bentos yaitu Lumbriculus sp. dan Nereis sp. Kedua jenis bentos yang ditemukan ini sama-sama termasuk Pylum Annelida http://animaldiversity. ummz.umich.edu/site/accounts/classification/ Annelida.html\#Annelida). Lumbriculus sp. termasuk dalam kelas Oligochaeta dan Nereis sp. termasuk dalam kelas Polychaeta. Daerah Pulau Payung berdekatan dengan daerah muara yaitu Sungsang sehingga pengaruh kadar garam ada sehingga dimungkinkan ditemukan jenis kelas Polychaeta. Jumlah Lumbriculus sp. lebih banyak dibanding Nereis sp., Lumbriculus sp. ada 16 ekor, sedangkan Nereis sp. cuma 3 ekor. Jadi dimungkinkan Oligochaeta lebih banyak di lokasi ini dibandingkan Polychaeta karena air cenderung semakin tawar. 
Tabel $1 . \quad$ Jenis-jenis makrozoobentos yang ditemukan dari daerah Pulau Payung

\begin{tabular}{lccc}
\hline No. & Nama genus & Jumlah (ekor) & Gambar \\
\hline 1. & Lumbriculus sp. & 16 & \\
\end{tabular}

2. Nereis sp.

3

Sumber: 1) http://www.sazp.sk/bisel/galerie/oligochaeta_enchytraeidae_haploxidae.htm; 2) http://io.uwinnipeg.ca/ simmons/ lb7pg2.htm

\section{KESIMPULAN}

1. Pada daerah Pulau Payung ditemukan Pylum Annelida antara lain Lumbriculus sp. dan Nereis sp.

2. Jenis-jenis bentos yang ditemukan ada 2 kelas yaitu Oligochaeta dan Polychaeta, tetapi Oligochaeta (Lumbriculus sp.) lebih banyak dibanding dengan Polychaeta (Nereis sp.).

3. Teknik pengambilan bentos dilakukan pada lokasi yang unsur lunak atau berupa lumpur.

\section{DAFTAR PUSTAKA}

Anonim. 2007. Oligochaeta. http://www.sazp.sk/ bisel/galerie/oligochaeta_enchytraeidae _haploxidae.htm
APHA. 2005. Standard Methods for the Examination of Water and Wasterwater $21^{\text {st }}$ Edition. American Public Health Association Inv. Washington.

Fachrul, M. F. 2007. Metode Sampling Bioekologi. PT. Bumi Aksara. Jakarta.

Hawkes, H. A.1979. Invertebrates as indicators of river water quality. Dalam: Biological Indicator of Water Quality. James, A. \& L. Evison (eds). New York. John Wiley and Sons.

Myers, P., R. Espinosa, C. S. Parr, T. Jones, G. S. Hammond, \& T. A. Dewey. 2006. The Animal Diversity Web. http:// animaldiversity.ummz.umich.edu/site/accounts/ classification/Annelida.html\#Annelida.

Simmons, K. 2007. The Clamworm (Nereis sp.). http:/ /io.uwinnipeg.ca/ simmons/ lb7pg2.htm. 